\title{
Characteristics and performance of soil, bentonite and conductive cement during impulse tests in Swaziland
}

\begin{abstract}
The essence of grounding in power systems is very essential. This paper presents the performance and characteristic of backfill material such as bentonite and conductive cement. The backfill materials pay a pivotal role in controlling ground impedance of the soil. Protective devices are normally used to divert an excessive current during lightning strikes through earth rode to avoid damages to the equipment. Swaziland has been experiencing a lot of power failures due to lightning especially during rainy season. Most of their transformers has been lost because of this problem. Most of Swaziland network is overhead which is exposed to lightning. It is thus important to design an effect earthing system that will be able to protect the equipment during fault conditions. In this study, it has been found that the behaviour of backfill material depends on the voltage applied. It was also found that the time to breakdown in comparison between bentonite and conductive cement. This paper highlights some of the aspects need to take into consideration for grounding for a country like Swaziland.
\end{abstract}

Keyword: Earthing; Impulse tests; Lightning; Soil resistivity 